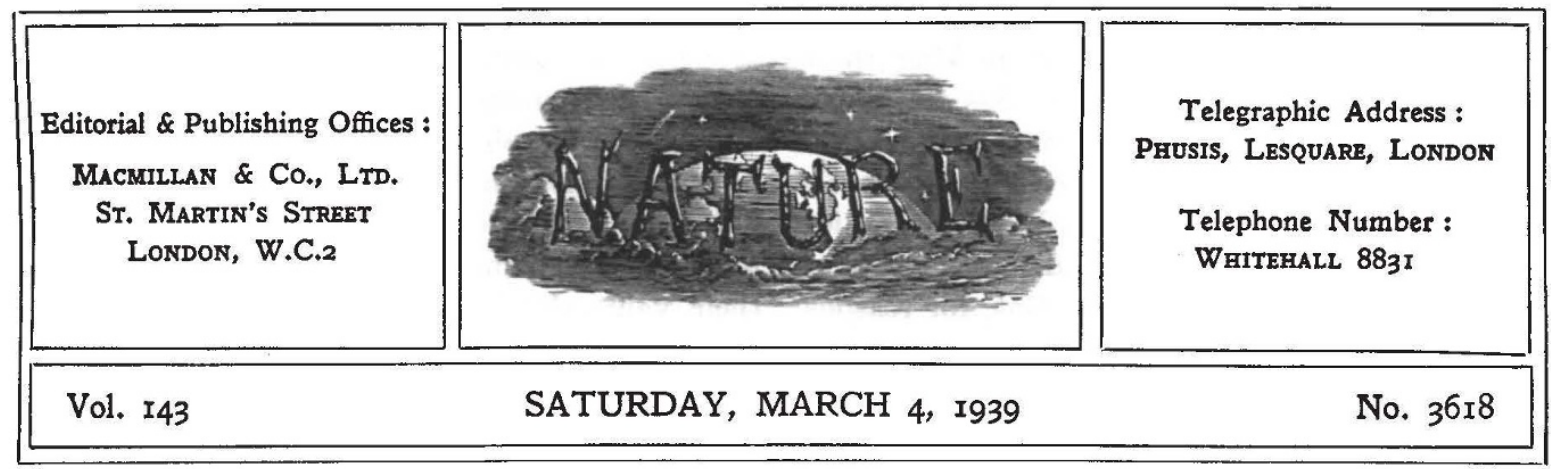

\title{
The Spens Report and Technical Education
}

$\mathrm{W}^{\mathrm{s}}$ HEN the report of the Board of Education's Consultative Committee on the Education of the Adolescent (afterwards known as the Hadow Report) was noticed in these columns (NATURE, Feb. 5, 1927), we recorded our regret that the position and importance of the junior technical school had not received adequate treatment. No such charge can be made against the Committee's recent report, now already widely known as the Spens report (see also Nature of January 21, p. 103, and February 18, p. 259, and p. 363 of this issue).

An outstanding recommendation is that there be established a new type of higher school of technical character quite distinct from the traditional academic grammar school, and as a first step towards that end "a number of existing junior technical schools oriented towards the engineering and building industries and any other technical schools which may develop training of such a character as $(a)$ to provide a good intellectual discipline altogether apart from its technical value, and (b) to have a technical value in relation not to one particular occupation but to a group of occupations should be converted into technical high schools".

It is the intention of the Committee that these schools shall be accorded, in every respect, equality of status with schools of the grammar school type. Clearly, if that intention is to be carried out, there must be equality in respect of the age of entry. Hitherto the age of entry into the junior technical school has been thirteen plus. That has meant that, since the secondary (grammar) schools recruited at the age of eleven, they have had the opportunity of taking the cream of the pupils before the junior technical school could have its chance of selection. If the Committee's recommendation be accepted, that grievance will be removed, for it has agreed "that pupils should be recruited for technical high schools at the age of 11 plus by means of the general selective examination by which pupils are at present recruited for the grammar schools".

That does not mean, however, that at the age of eleven years the curriculum will be what is called 'vocational'. Nor does it mean that, at any time during the course, it will be 'vocational' in its narrowest sense. Indeed, the Committee has been careful to guard in advance against the charge that its views may involve "the danger of premature specialization of a vocational character". It is pointed out, and in our view rightly, that much of the fear of vocationalism has arisen through misunderstanding and failure to define the term and to face the facts of educational development. The Committee underlines a point which had been made more than once in these columns: that, "in any subject worthy of inclusion in a school curriculum, it should be possible to lead the pupil to look beyond the immediate processes in which he is engaged to a wider human and social background"; and if that be not the path towards a really liberal and humane education, we confess that our own views stand in need of considerablo revision. With that, and all its implications in mind, the Committee has recommended that the curriculum for pupils between the ages of eleven plus and thirteen plus in technical high schools should be broadly of the same character as the curriculum in other types of secondary schools of equal status. For pupils above the age of thirteen years the curriculum "should be designed so as to provide a liberal education with science and its applications as the core and inspiration". 
Let there be no mistake : in making these recommendations the Committee has in mind certain junior technical schools and those alone. There are, under the general heading of schools providing technical education, trade schools, junior commercial schools, junior art departments and home training schools for girls. But, for reasons which the Committee examines with some care, and with which there will be a large measure of agreement, it is not prepared to say that such schools shall become technical high schools.

It may be, of course, that, just as some pupils after two years in a grammar school may be recognized as those who would gain the greatest educational benefit in a technical high school, there will be pupils of the latter who will be recognized as those who will profit most from the education of the grammar school. No system of education can be allowed to develop rigidity without diminution of its full possibilities. We are glad, therefore, to note that the Committee has recommended that there should be close relations between grammar schools and technical high schools, "so that the opportunity of transfer at about the age of 13 should exist for those pupils whose later development would be better suited by an alternative form of education".

Equality of status is further emphasized by a suggestion that the fees for technical high schools should be the same as those in grammar schools in the same administrative area. While fees exist, we believe that is a wise suggestion. We need not here go into the reasons for that belief. It is sufficient to say that there are still people who believe (and they are not altogether to be blamed) that the cost of an article is the truest indication of its value.

Hitherto, the junior technical school has perhaps owed a much larger measure of its success than is usually realized to its freedom from examinations. But, if equality is to be ensured, the present value $\theta$ placed by some upon the School Leaving Certificate is not to be neglected. In connexion with that certificate the Committee has expressed itself in terms discussed in NatoRe of February 18. While, however, the Committee recommends that technical high schools should have some kind of school leaving certificate which will have general currency and bring before parents, employers and the public generally the fact that these schools are of equal status with the grammar schools, it guards, and very wisely in our view, against the imposition of a rigid external examination. Accordingly it suggests an examination similar to the national certificate examinations, which have worked so well in senior technical colleges and which permit of internal examination with external assessment.

No one would deny that, if the fullest benefit is to be derived from the new technical high schools, their value should be made clear to all. "We find," says the report, "that there is much ignorance and misunderstanding of the aims, scope and work of the technical schools." The modern way of treating a defect of that kind is the way of publicity. The Committee does not shrink from that. "We think that education authorities might be well advised to give greater publicity to the aims and character of their technical schools, both to industry and to the general public. We have already indicated one or two reasons why the general public should know and appreciate more the work of these technical schools; but there is at least one excellent reason for directing towards them the keener attention of industry."

That reason involves the question of apprenticeship, and we agree with the Committee that this should receive the immediate and earnest consideration of industry. The conditions of apprenticeship should be re-examined if only because there appears to be no uniformity of practice. Some firms will not accept a boy after the age of sixteen years. Some will do so, but insist that his apprenticeship should not end until five years after the date of his entry. Others will accept after sixteen years of age and will remit a period equivalent to that between the date of his sixteenth birthday and the date of his acceptance into industry. Others, still, will remit one year of apprenticeship to a boy who has satisfactorily completed a three-year course at an approved technical school. That, surely, is a position which needs alteration, and we feel with the Committee that it should be considered by employers' associations and by trade unions in order that a definite pronouncement of policy should be made. We do not think the Committee exaggerates when it says "a wise industrialist will be prepared and even eager to take as apprentices boys who have completed a technical school course at the age of 16 plus and should at least grant remission of that period between the sixteenth birthday and the date of actual commencement of apprenticeship, so that in all cases the apprenticeship would be completed on the twenty-first birthday."

It will be observed that, throughout what we have said, there have been no recommendations 
affecting the senior technical colleges. That is to be expected, because the senior colleges did not come within the Committee's terms of reference. It may be noted here that the new technical high schools will, where possible, be housed in, and be departments of, technical colleges. The head master of the school will be the head of that department. Even where the school cannot be housed in the college, it is recommended that "its buildings should be linked with buildings of the college in order to facilitate participation in equipment and staff". The school, however, should have its own sub-committee of governors to whom the head master should have direct access.

We welcome the Committee's suggestion of the new technical high school not only because it is needed as part of a unified system of secondary education, but also because it recognizes the liberal quality inherent in technical education, and, in doing so, it faces what it has itself called the facts of educational development. It recognizes the efforts which are being made to evolve a new type of secondary school "providing a liberal education, based on a more realistic and scientific curriculum than that of a grammar school", and in doing so it underlines a point which we have made more than once in these columns : that culture is not necessarily an unchanging quality, but something which may change with the progress of mankind. Perhaps, then, it is not too great an exaggeration to say that, behind the apparently sombre and shapeless civilization which we are making, there lies the possibility of a nobler culture than has yet been known.

\section{Some Seventeenth Century Astronomers}

Hevelius, Flamsteed and Halley :

Three Contemporary Astronomers and their Mutual Relations. By Eugene Fairfield MacPike. Pp. ix $+140+4$ plates. (London: Taylor and Francis, Ltd., 1937.) 12s. 6d. net.

IN this book the editor of the "Correspondence and Papers of Edmond Halley" has brought together brief, straightforward lives of the three great astronomers named in the title; a separate consideration of their commerce together and mutual relations; and, in appendixes, several documents and letters concerning them, chiefly Hevelius. Where the pieces are in Latin a translation has in some, but not in all, cases been furnished by the pen of Mr. A. H. White.

This method of assembling the information set before the reader is not without its disadvantages, for it is bound to lead to either gaps or repetitions. Thus, in the life of Halley, only passing reference is made to the extremely important visit to Hevelius, when Halley tested telescopic sights against the open sights always used by the Danzig astronomer. This matter is dealt with at length in the joint consideration of the three astronomers, while the matter of the piracy, or call it what you will, of Flamsteed's observations is considered, with considerable repetition, in both the separate and the joint life. The book is, perhaps, rather a collection of valuable notes than balanced biography.

In his preface, the author refers to a manuscript autobiography of Flamsteed, preserved at
Greenwich, which he has used. This may account for the uneven style of the life, which is a mixture of the modern idiom and typical seventeenth century phrases, taken, we hazard, unchanged from the source, such as, for example, the following: “. . . lent him Sacrobosco's Spheres, in Latin, a work which, being perfectly suited to the natural turn of his genius, he perused with uncommon satisfaction", and elsewhere we find "dioptrics" and "Sir Clowdisley Shovell" used in the ordinary text. The life of Halley is much fuller than the others, in accord with the author's special interest. The quarrel between Flamsteed and Halley is discussed at some length, and put down to Flamsteed's jealousy, as in a sense it may have been, but Flamsteed was a man who had suffered many genuine wrongs, who had spent his scanty private means and all his energies freely in the service of astronomy and who had "endured long and painful distempers". Perhaps he was jealous of the genial, social, worldly and successful Halley, who must certainly have been a very much more entertaining companion, but it is a jealousy that may excite our pity rather than our scorn.

The book is of great interest to those concerned not only with the astronomers themselves but also with Hooke, for it was Hooke who in his "Animadversions on the first part of the Machina Coelestis" first insisted on the advantages of telescopic sights over open sights, and clearly explained the nature of optical resolution. The tests which Halley carried out at Danzig with telescopic sights and with the instruments of Hevelius frequently come 